\title{
Sternal-sparing Jarvik 2000 implantation, heart transplantation and driveline pedestal removal
}

\author{
Antonio Loforte, Gregorio Gliozzi, Giuditta Coppola, Giulio Giovanni Cavalli, Sofia Martin Suarez, \\ Davide Pacini \\ Division of Cardiac Surgery, IRCCS Azienda Ospedaliero-Universitaria di Bologna, Bologna, Italy \\ Correspondence to: Dr. Antonio Loforte, MD, PhD. Cardiac Surgeon, Department of Cardiac Surgery, S. Orsola Hospital, ALMA Mater Studiorum \\ University of Bologna, Via Massarenti n.9, 40138 Bologna, Italy. Email: antonioloforte@yahoo.it.
}

Submitted Nov 04, 2020. Accepted for publication Feb 08, 2021.

doi: 10.21037/acs-2020-cfmcs-27

View this article at: http://dx.doi.org/10.21037/acs-2020-cfmcs-27

\section{Introduction}

We describe our institutional sternal-sparing approach for Jarvik 2000 (Jarvik Heart, Inc., NY, USA) intraventricular axial flow left ventricular assist device (LVAD) (1-5) implantation and further heart transplantation surgery with details on pedestal cable removal.

\section{Clinical vignette}

A fifty-seven-year-old male was admitted to our institution with a diagnosis of advanced heart failure due to ischemic dilated cardiomyopathy. The patient required inotropes and intra-aortic balloon pump support. Echocardiography showed a dilated left ventricle (LV) with an ejection fraction of $20 \%$, associated with severe mitral valve regurgitation. Right heart catheter assessment documented a severe reduction of cardiac output $(\mathrm{CO},<2.0 \mathrm{~L} / \mathrm{min})$ and severe pulmonary hypertension [pulmonary vascular resistance (PVR), $>8$ Woods units].

The patient was considered ineligible for a heart transplant (Htx) and LVAD implantation was scheduled.

\section{Operation}

Postauricular pedestal placement and Jarvik 2000 implantation

The patient was placed in a $45^{\circ}$ right decubitus position, with the left arm over the head.

Before heparinization, a "C-shape" skin incision in the retroauricular region was performed to prepare a large- based flap above the ear. The subcutaneous tissue was dissected and periosteum slit. Six holes were drilled in the bone with a specific $6 \mathrm{~mm}$ long drill and the pedestal was temporarily implanted.

Muscle sparing anterolateral thoracotomy through the 6th intercostal space was used and left groin vessels exposed for safety.

Once the lateral thoracotomy was performed, two skin incisions in the postero-lateral side of the neck and shoulder were made to create a subcutaneous tunnel extending from the upper chest to the mastoid region. When the Jarvik 2000 was moved into the field, the power-cable with the three-pin connector was guided through this tunnel, into the second intercostal space and connected to the pedestal, which was fixed with self-tapping screws. The skin flap was repositioned, leaving the connector free for coupling with the external cable.

Through the thoracotomy access, the left inferior pulmonary ligament was divided and the lungs retracted. The descending aorta was exposed below the lung hilum and above the diaphragm. The pericardium was incised, the $L V$ apex exposed and without cardiopulmonary bypass $(\mathrm{CPB})$, the sewing ring was sutured using 3-0 polypropylene with Teflon felt support.

The outflow graft was anastomosed with a running 4-0 polypropylene suture and was directed towards the aortic arch. In the Trendelenburg position, a transmural cruciate incision inside the sewing ring was performed and, the Jarvik 2000 pump pushed into the ventriculotomy. As the pump was placed in the apex, the internal connecting umbilical ring strings were tied. The pump was switched 
on for deairing and secured in the cuff by tightening the external strings. The device speed was increased according to the hemodynamics. Protamine sulfate was used to reverse the heparin.

The postoperative course was uneventful and the patient was successfully discharged home on postoperative day twenty-three. Right heart catheter evaluation documented a normalization of PVR (<2 Woods units) within one-year of mechanical support and, as a result, the patient was placed on the official waiting list for Htx.

\section{Heart transplantation}

After 2,757 days (almost 7.8 years) of LVAD support, Htx was performed.

A full sternotomy was performed. The aorta, main pulmonary artery trunk, superior vena cava (SVC) and inferior vena cava (IVC) were isolated.

After systemic heparinization, CPB was established by direct cannulation of the SVC and IVC for venous drainage and, the distal ascending aorta for arterial return. The Jarvik pump cuff and the proximal outflow graft tract lie posteriorly thus keeping all anterior and right mediastinum free of pump components which are, instead; easily isolated from the left lateral pericardium. The distal tract of the conduit lies into the left pleural cavity. Thus, an accurate debridement of adhesions was performed with removal of prior Gore-Tex membrane.

When the donor heart arrived in the operating room, the recipient ascending aorta is cross-clamped, the pump stopped and the outflow graft narrowed distally. The right atrium was opened in its anterolateral wall and the interatrial septum incised to allow the $L V$ to empty via the mitral valve. The aorta and pulmonary artery were divided above their respective semilunar valves. The SVC was transected at its cavo-atrial junction, and a large cuff of the IVC was prepared by trimming the atrial wall, carrying it medially through the ostium of the coronary sinus and laterally through the fossa ovalis. The left atrial cuff was prepared by entering the roof of the left atrium, the heart was lifted anteriorly, the outflow graft cut and distally sutured at the anastomosis on the descending aorta, using a polypropylene $4 / 0$ running suture and leaving a Dacron graft islet on site, while the cable lead was interrupted.

The Htx anastomoses are performed according to the following sequence: left atrium, IVC, SVC, pulmonary artery and aorta (all running 5-0 polypropylene sutures).
After the reperfusion period, the patient was gradually weaned from CPB.

\section{Pedestal and cable removal}

Pedestal and cable removal has been scheduled electively thirty days after Htx.

The operation was performed with the patient awake, under local anesthesia. The surgical procedure was performed when the patient is fully mobilized.

The site of operation required the head to be in a semilateral decubitus position. An incision was made around the pedestal to create a semi-circular, cutaneous flap, which was pulled aside to expose the base of the pedestal. The six screws are twisted off and the pedestal is separated from the bone. The Dacron sheath protecting the power cables was separated from adhesions thus, allowing cables to be removed.

\section{Outcome}

The postoperative course was uneventful and the patient was successfully discharged home without occurrence of transplant-related adverse events.

\section{Comments}

For patients who are transplant candidates, keeping the sternum intact is an important advantage, allowing a safe reentry (2-4). Avoidance of CPB may prevent deterioration in pulmonary gas exchange and reduce postoperative bleeding (2-4). However, this approach precludes a full inspection of the $\mathrm{LV}$, especially for thrombi.

The absence of a bend relief and the sharp angle coming off the intraventricular position, makes Jarvik 2000 offpump insertion relatively straightforward (2-4).

Due to its solid fixation in well vascularized tissue, the skull driveline pedestal implant is resistant to infection and allows patients to be fully immersed in water thus, providing high quality of life $(2,3,5)$.

To our knowledge, this is the longest reported patient who has been supported by his original Jarvik 2000 pump, whilst awaiting Htx for 7.8 years (2).

\section{Acknowledgments}

Funding: None. 


\section{Footnote}

Conflicts of Interest: The authors have no conflicts of interest to declare.

Open Access Statement: This is an Open Access article distributed in accordance with the Creative Commons Attribution-NonCommercial-NoDerivs 4.0 International License (CC BY-NC-ND 4.0), which permits the noncommercial replication and distribution of the article with the strict proviso that no changes or edits are made and the original work is properly cited (including links to both the formal publication through the relevant DOI and the license). See: https://creativecommons.org/licenses/by-nc-nd/4.0/.

\section{References}

1. Cooley DA. Initial clinical experience with the Jarvik

Cite this article as: Loforte A, Gliozzi G, Coppola G, Cavalli GG, Martin Suarez S, Pacini D. Sternal-sparing Jarvik 2000 implantation, heart transplantation and driveline pedestal removal. Ann Cardiothorac Surg 2021;10(2):295-297. doi:10.21037/acs-2020-cfmcs-27
2000 implantable axial-flow left ventricular assist system. Circulation 2002;105:2808-9.

2. Selzman CH, Koliopoulou A, Glotzbach JP, et al. Evolutionary Improvements in the Jarvik 2000 Left Ventricular Assist Device. ASAIO J 2018;64:827-30.

3. Zucchetta F, Tarzia V, Bottio T, et al. The Jarvik-2000 ventricular assist device implantation: how we do it. Ann Cardiothorac Surg 2014;3:525-31.

4. Gerosa G, Gallo M, Tarzia V, et al. Less invasive surgical and perfusion technique for implantation of the Jarvik 2000 left ventricular assist device. Ann Thorac Surg 2013;96:712-4.

5. Tarzia V, Di Giammarco G, Di Mauro M, et al. From bench to bedside: Can the improvements in left ventricular assist device design mitigate adverse events and increase survival? J Thorac Cardiovasc Surg 2016;151:213-7. 